\title{
Synthesis of Si /rgo Nano-composites as Anode Electrode for Lithium-ion Battery by Ctab and Citrate Methods: Physical Properties and Voltage-capacity Cyclic Characterizations.
}

\section{H. Torkashvand}

Damghan University

M.-M. Bagheri-Mohagheghi ( $\sim$ bmohagheghi@du.ac.ir)

Damghan University https://orcid.org/0000-0002-8642-7456

\section{Research Article}

Keywords: Porous SiNPs - rGo nano-composite, Thermal reduction, Li-ion Battery, Anode electrode

Posted Date: March 5th, 2021

DOl: https://doi.org/10.21203/rs.3.rs-271537/v1

License: (c) (i) This work is licensed under a Creative Commons Attribution 4.0 International License.

Read Full License 


\section{Abstract}

In this paper, SiNPs / rGO nano-composites were prepared from porous silicon nanoparticles synthesized by silica mineral $\left(\mathrm{SiO}_{2}\right)$. Reduced graphene oxide $(\mathrm{rGO})$ was synthesized by thermal reduction method.

The Si NPs/rGO nano-composite synthesized by three methods using the (a) CTAB as surfactant (b) CTAB as surfactant and citric acid as a functional group and (c) without CTAB and with citric acid under ultrasonic condition. The samples were analyzed by X-ray Diffraction (XRD), Field Emission Scanning Electron Microscopy (FE-SEM), VU-Vis, EDX and FTIR spectroscopy.

The test of anode electrode sample for synthesis (a) carried out by potential $\left(\mathrm{Li}^{\mathrm{L}} \mathrm{Li}^{+}\right)$vs. capacity measurements. The anode made of the resulting nano-composite showed an initial specific capacity of $1191 \mathrm{mAhg}^{-1}$ and specific capacity of $845 \mathrm{mAhg}^{-1}$ after 10 cycles at a current density of $100 \mathrm{mAg}^{-1}$ and a coulomb efficiency of approximately $99.4 \%$ after these cycles. Porous nanoparticles have improved the electrochemical properties of the nano-composite along with the conductivity and buffering properties of rGO by creating a suitable space for lithiation/delithiation process.

\section{Introduction}

Market push to acquisition high-capacity Li-ion battery (LIBs) technology for electronics and electrical vehicles, has driven the intense research and develop toward new anode materials. In addition, Silicon (Si) is considered as an attractive candidate because its high specific capacity (4200 mAhg ${ }^{-1}$ ) and low discharging voltage $\left(0.37 \mathrm{mV}\right.$ vs $\left.\mathrm{Li}^{\prime} \mathrm{Li}^{+}\right)$that is very close to lithium [1-4].

Si-Graphene nano-composites have been widely considered in the fabrication of LIBS battery anodes since 2010 due to their potential to improve cycling performance [5]. The main factors that prevent the replacement of graphite-based anodes with Si-based one in these batteries are the enormous volume expansion during lithiation, slow diffusion rate of lithium and low electrical conductivity. Si nanostructures and carbon derivatives are used to overcome these problems [6]. Carbon compounds improve conductivity and the addition of Si stabilizes the solid electrolyte interface (SEI) layer [7].

Si has a high theoretical gravimetric capacity of $4200 \mathrm{mAhg}^{-1}$. Volumetric expansion of $\mathrm{Si}(>300 \%)$ during lithiation/de-lithiation process causes cracking and breakage [8-11]. On the other hand, Si has poor electrical conductivity and low lithium-ion diffusion capacity due to its semiconductor nature [12]. To overcome this problem, Si nanostructures with different configuration including core-shell structures, nanoparticles, nanowires and porous Si are used while nano size affects specific capacity [13-15]. Si nanoparticles with porous structure provide volume expansion and prevent pulverization [16-18].

Graphene has attracted much attention due to its unique electrical and optical properties $[19,20]$. The graphene band gap is zero [21,22]. This has limited its use in nanoelectronics. With the band gap engineering in graphene, many applications are obtained for it [23-26]. Graphene oxide (GO) and its relative reduction can be used to adjust the band gap in graphene [27, 28]. It has a high potential for the 
synthesis of carbon-based nanostructures that can be obtained on a large scale from the oxidation of inexpensive graphite. The properties of the final product can be adjusted by reducing $\mathrm{GO}$ in various ways and controlling the reduction conditions [29].

GO reduction increases the mobility of charge carriers and absorption and tune the band gap in which the photo responsivity can be adjusted by controlling defects and oxygen groups [30,31].

Go is generally electrically insulator because of the existence of substantial $\mathrm{sp}^{3}$ hybridized carbon atoms bonded with oxygen. The alteration of $\mathrm{sp}^{2}$ and $\mathrm{sp}^{3}$ carbon segments present in graphene oxide are beneficial for the manipulation of its bandgap, therefore controlling the transformation of graphene oxide from an insulator to a semiconductor [32].

Various chemical, thermal, electrical, or a combination of methods have been reported to produce reduced graphene oxide (rGO) [27]. The rGO has a low reversible capacity as a host in the nano-composite, but as a conductor and buffer it can improve the electrochemical performance of Si nanoparticles.

Graphene reduces the surface contact of Si nanoparticles with the electrolyte (SEI) and improves the electrical conductivity of the electrode. The empty space between Si nanoparticles and graphene provides the space needed for volumetric changes in working cycles [33].

Several methods have been reported for the synthesis of Si-graphene nano-composites: mixing the synthesized Si nanocrystals with graphene or graphene oxide Physically or by chemical vapor deposition (CVD) [34]. Direct growth of graphene on Si nanoparticles, Si coating on graphene by CVD, thermal reduction [35], freeze drying / thermal reduction [36-39], spray drying / thermal reduction [40], microwave drying / thermal reduction [41] is used to make Si-graphene nano-composite.

The physical methods for the synthesis of stable Si-graphene nanocomposites are difficult. Although, the CVD method is usually complex, time consuming and expensive [42], Zhu et al. synthesized nanocomposite of Si-graphene by using plasma-assisted milling route [43].

Thermal reduction method is a simple and mass-produced method for the production of Si-Graphene nano-composites [42]. This method has been used by different groups to prepare SiNPs-Graphene nanocomposites [44- 46].

In this study, porous Si NP-rGO nano-composite was synthesized by thermal reduction method as an anode electrode for LiBs. Three different compounds were prepared by thermal reduction synthesis using (a) CTAB additive (b) CTAB and Citric acid and (c) Citric and only ultrasound assisted. The samples were analysis by X-ray Diffraction (XRD), Field Emission Scanning Electron Microscopy (FE-SEM), VU-Vis, EDS and FTIR spectroscopy. The structural properties of nano-composites including crystallinity, surface morphology, the optical behavior (optical band gap) and electrochemical performance for nanocomposite synthesized with CTAB additive were investigated. Also, test of anode electrode sample carried out by potential $\left(\mathrm{Li}^{\mathrm{L}} \mathrm{Li}{ }^{+}\right)$vs. capacity measurements. 


\section{Experimental Methods}

\subsection{Materials}

Si nanopowder (20-40 nm), Cetyl Trimethy Ammonium Bromid (CTAB), GO (15 nm thickness multilayer, 5micron particle size, Armina Eng.Co), $\mathrm{C}_{6} \mathrm{H}_{8} \mathrm{O}_{7}$ (Merck, 99\%), $\mathrm{HCl}$ (37\% Merck), HF (99.8\% Sharlau), $\mathrm{H}_{2} \mathrm{O}_{2}$ (30\% Merck), $\mathrm{CH}_{3} \mathrm{COOH}$ (99.5-100\% Ghatran-Shimi), Ethanol, Dionized water.

\subsection{Synthesis of Si NP-rGO nano-composite}

In this work, the synthesis of Si NPs-rGO nano-composite was performed in the following three synthesis:

Synthesis 1: $0.05 \mathrm{gr}$ of reduced graphene oxide ( $\mathrm{rGO}$ ) was dissolved in $10 \mathrm{cc}$ of deionized water. Then, $0.015 \mathrm{gr}$ of prepared porous Si nanopowder, synthesized in the previous work [47], and $0.05 \mathrm{gr}$ of CTAB material were added to the rGO solution. CTAB as a surfactant consists of a hydrophilic cationic polar head and a hydrophobic sequence, it is able to bond Si nanoparticles to graphene.The resulting solution was stirred on a magnetic stirrer for 10 hours at $T=100^{\circ} \mathrm{C}$ and dried. Then, the obtained material was annealed in an oven under argon gas at $\mathrm{T}=500^{\circ} \mathrm{C}$ for 2 hours. It was then filtered using a paper filter and washed with $\mathrm{HF}$, alcohol, deionized water and finally dried under vacuum at $\mathrm{T}=70^{\circ} \mathrm{C}$ overnight. Synthesis 2. In another method, $0.05 \mathrm{~g}$ of reduced graphene oxide ( $\mathrm{rGO}$ ) was dissolved in $10 \mathrm{cc}$ of deionized water and $0.015 \mathrm{~g}$ of Si nanopowder, $0.05 \mathrm{~g}$ of CTAB and $0.05 \mathrm{~g}$ of citric acid as a hydroxyl functional group were added.Citric acid is a hydroxy acid, a group of carboxylic acids to which a hydroxyl functional group has been added. Then, the reflux process was performed on the resulting solution at $\mathrm{T}=100^{\circ} \mathrm{C}$ for 2 hours and then dried. After this step, the material was annealed like the previous method. Synthesis 3. $0.001 \mathrm{~g}$ of Si nanopowder was mixed with $2 \mathrm{cc}$ of deionized water and placed in ultrasonic for 10 minutes. Then, $1.25 \mathrm{cc}$ of reduced graphene oxide ( $\mathrm{rGO})$ solution in water $(1 \mathrm{mg} / \mathrm{ml})$ was added to it and placed in ultrasonic for 2 hours.After drying, the resulting mixture was annealed in furnace under $\mathrm{N}_{2}$ gas at $\mathrm{T}=750$ ${ }^{\circ} \mathrm{C}$ for 2 hours. After approximately 10 hours, the oven was cooled and the composition was taken out of the furnace and powdered in an agate mortar. In the last step, to remove impurities and residual oxide layers, it was washed with $\mathrm{HF}$, alcohol, deionized water and finally dried under vacuum at $\mathrm{T}=70^{\circ} \mathrm{C}$ overnight.Figure 1 (a) and (b) shows a schematic view of the 2D network structure and the final nanocomposite of SiNPs-rGO nano-composite.

\section{Results And Discussion}

\section{1: Structural studies of Si NPs- rGO nano-composites by XRD and EDX analysis}

In order to study the structural properties of Si NPs / rGO nano-nano-composites, XRD patterns was taken from three synthesis processes. The XRD spectra of the Si NPs-rGO nano-composite are shown in Figure 2. The peaks observed at the angles $2 \theta=28.52^{\circ}, 47.23^{\circ}, 56.31^{\circ}, 69.30^{\circ}$ and $2 \theta=76.41^{\circ}$ correspond to the crystal plates (111), (220), (311), (400) and (331) respectively, are related to Si nanoparticles. The graphite peak (C) in the samples at $2 \theta=26.28^{\circ}$, the peak for rGO at $2 \theta=44^{\circ}$ and the broad peak in the 
range $2 \theta=20-27^{\circ}\left(\right.$ maximum at $\left.2 \theta=23^{\circ}\right)$ has been specified. The present patterns confirm the formation of Si NPs-rGO nano-composite [48, 49].Also, the EDAX spectrum from the nano-composite and the results of elemental analysis using its data are shown in Fig 7 and Table 1 respectively.

\section{3-2: Morphology of Si NPs-rGO Composition}

The FESEM images of the synthesis1 for nano-composite using CTAB as a surfactant, are shown in Figure 4 (a) to (c).

These images show the layered $\mathrm{rGO}$ and folded structure (with a relative thickness of $50 \mathrm{~nm}$ according to the scale of the images). The presence of Si nanoparticles as a mass on graphene plates indicates the formation of Si NPs-rGO nano-composite.

In the synthesis 2, CTAB was used as surfactant and citric acid as a functional group. The FESEM images of the nano-composite synthesized by this method are shown in Figure 5 (a) to (d).

The use of organic molecules such as citric acid as a binder has a unique effect on Si anode stabilization due to its flexibility and non-toxic properties.

This acid reacts with GO functional groups due to carboxyl and hydroxyl functional groups and therefore causes Si nanoparticles to adhere to graphene plates [50]. Also, the presence of this acid and the CTAB prevented the nanoparticles from bonding to each other and caused the nanoparticles to spread on all rGO surfaces.As previously mentioned, in the synthesis 3 , ultrasonic was used for the initial combination of Si and GO powder. The FESEM images of the nano-composite synthesized by this method are shown in Figures 6 (a) and (b). The dimensions of the nanoparticles are shown in the figure, which are in the range of 36-57 $\mathrm{nm}$.As can be seen from the microscopic images in Fig 6, the layered graphene structure exists in all three methods. In the first method, the number of graphene layers is limited, with a relatively flat surface with Si nanoparticles attached to the graphene plates (binding state). In the second method, the number of graphene layers is increased, the degree of smoothness of graphene surfaces is reduced and Si nanoparticles are placed on the plates and between the graphene plates (layering state). In the third method, graphene plates are Tangled in shape with more layers that contain Si nanoparticles (folding state).It should be noted that the ratio of Si nanoparticles to graphene have a particular importance in the performance of the nano-composite fabricated as the anode of lithium batteries. The higher the Si value, the higher the initial battery capacity and the faster the capacity fading. The ratio of $40 \%-60 \%$ carbon for this nano-composite has been reported by researchers [51].The operating conditions of Si-rGO nano-composites depend on their morphology. The best-case scenario is when Si NPs are homogeneously distributed among the graphene plates. The uniform distribution of graphene sheets also increases the electrical conductivity of this nano-composite [52]. These conditions are observed in the second and third synthesis methods so that the nanoparticles are placed with a more uniform distribution between the graphene plates. The use of ultrasonic in the third method, is effective in the uniformity and homogeneous distribution of Si nanoparticles.3-3: Optical band gap for Si NPs-rGO nano-compositeln order to determine optical band gap of samples, the curves (ahv) $)^{1 / 2}$ and (ahu) ${ }^{2}$ in terms of $h \otimes$ were 
plotted in Figures 7(a) and (b). The intersection of the red lines with the horizontal axis indicates the amount of the gap. As can be seen from the graph, the value of the indirect band gap is equal to $4.15 \mathrm{eV}$, that indicates a slight increase over the pure sample of Si nanoparticles. The value of the direct band gap showed two values of $3.45 \mathrm{eV}$ and $5.36 \mathrm{eV}$.In synthesized nano-composite samples, the addition of $\mathrm{Si}$ nanoparticles opens the optical gap and due to the hybridization between the $\mathrm{s}$ and $\mathrm{p}$ orbitals of $\mathrm{C}$ and $\mathrm{Si}$ atoms, the $\sigma$ bonds are slightly altered while $\pi$ bonds are substantially modified.3-4: Molecular structure

\section{of synthesized nano-composite samples by FTIR}

Figure 8 (a) and (b) shows the FTIR spectra of SiNP-rGO-CTAB and SiNP-rGO-CTAB-Acid Citric nanocomposites respectively.

The peaks at $3445 \mathrm{~cm}^{-1}$ and $1147 \mathrm{~cm}^{-1}$ are the anti-symmetric stretching vibration of $-\mathrm{OH}$ and the typical asymmetric stretching vibration of Si-O-Si of SiNPs. The next peaks at 1735, 1624, 1226, and $1049 \mathrm{~cm}^{-1}$ of $\mathrm{GO}$ correspond to the $\mathrm{C}=\mathrm{O}$ stretching, $\mathrm{C}=\mathrm{C}$ stretching, $\mathrm{C}-\mathrm{OH}$ stretching, and $\mathrm{C}-\mathrm{O}$ stretching vibrations, respectively [53-55]. O-Si-O bending vibration, symmetric elastic vibration of Si-O-Si and $\mathrm{Si}-\mathrm{O}-\mathrm{Si}$ asymmetric elastic vibration are ascribed to peaks at about $468 \mathrm{~cm}^{-1}, 816 \mathrm{~cm}^{-1}$, and $1087 \mathrm{~cm}^{-1}$ respectively [56].For $\mathrm{GO}$, the presence of the two peaks at $1715 \mathrm{~cm}^{-1}$ and $1050 \mathrm{~cm}^{-1}$ corresponding to the stretching vibration of $\mathrm{C}=\mathrm{O}$ for $-\mathrm{COOH}$ and $\mathrm{C}-\mathrm{O}$ for $\mathrm{C}-\mathrm{OH}$, respectively. new peak forming at $1628 \mathrm{~cm}^{-1}$ is attributed to the $\mathrm{C}=0$ stretching vibration of amide [57].GO exhibits many absorption peaks due to it functional groups, with the peak at $1730 \mathrm{~cm}^{-1}, 1608 \mathrm{~cm}^{-1}, 1220 \mathrm{~cm}^{-1}$, and $850 \mathrm{~cm}^{-1}$ corresponding to $\mathrm{C}=0$ stretching vibrations, $\mathrm{C}=\mathrm{C}$ stretching vibrations, $\mathrm{C}-\mathrm{O}$ symmetric stretching and deformation vibrations of the epoxy groups, respectively [58].

The IR peaks corresponding to $2927 \mathrm{~cm}^{-1}$ and $2849 \mathrm{~cm}^{-1}$ are due the asymmetric and symmetric $\mathrm{CH} 2$ stretching of GO respectively while the peak around $1619 \mathrm{~cm}^{-1}$ is attributed to $\mathrm{C}=\mathrm{C}$ stretches from unoxidized graphitic domain. The peak at around $1720 \mathrm{~cm}^{-1}$ is attributed to $\mathrm{C}=0$ stretch of carboxyl group, $1224 \mathrm{~cm}^{-1}$ corresponds to $\mathrm{C}-\mathrm{OH}$ stretch of alcohol group [59]. The peak at around $2923 \mathrm{~cm}^{-1}$ is attributed to $\mathrm{C}-\mathrm{H}[60]$.

\section{3-5: Electrochemical measurements of NP-Si/ r-GO nano- composite for anode electrode}

In order to perform the battery test, CR2035 half-cell battery was prepared. The working electrode was prepared by doctor-blade method, combining the active substance with a mass ratio of $90 \%$ SiNP-rGO powder, 5\% CMC (Carboxy Methyl Cellulose-Sodium) as binder and 5\% black carbon. The slurry was then coated on a $100 \mu \mathrm{m}$ thick copper foil, pressed and dried under vacuum at $\mathrm{T}=100^{\circ} \mathrm{C}$ for approximately 24 hours. Mass loading of electrode was $3.3 \mathrm{mg} / \mathrm{cm}^{2}$. Since the electrolyte used in the battery and the subsequent assembly process is very sensitive to moisture, the coin cell was assembled in an argon-filled glove box. 1.0 $\mathrm{M} \mathrm{LiPF}_{6}$ as electrolyte and polypropylene (Celgard 2300) as the separator (a layer of lithium-ion permeable film for preventing direct contact between the anode and the cathode) were used. The cut-off voltage used for charging and discharging was $0.001 \mathrm{~V}$ and $3 \mathrm{~V}$ (versus $\mathrm{Li} / \mathrm{Li}^{+}$), respectively. 
The electrochemical performances were tested on a NEWARE battery test system at room temperature. Fig 9 (a-c) shows the anode and coin cell battery made and a view of the battery tester used for analyze. Electrochemical measurements were used to investigate the kinetics of lithium-ion transfer during the processes of lithiation/delithiation for the anode made of SiNP-rGO nano-composite.

During the formation (the first charge / discharge steps after cell assembly) the part of lithium that is available by the electrolyte and the positive electrode, used to formation of SEl layer on The surface of graphene [61].

The SEl layer is a surface film formed by the decomposition of electrolyte on the anode surface. This film protects the electrolyte from further decomposition and also affects safety, capacity, power, cycle life and battery performance [62].

Figure10 shows the charge-discharge curve for the first 4 cycles and the 10th cycle of Si-rGO nanocomposite with a current density of $100 \mathrm{mAg}^{-1}(0.1 \mathrm{C})$ and voltage range of $0.001-3.0 \mathrm{~V}$.

The first discharge and charge capacities of the SiNP-rGO anode are approximately 1191 and 1212 $\mathrm{mAhg}{ }^{-1}$ respectively, which are $\otimes 3$ times higher than the gravimetric capacity of graphite $\left(372 \mathrm{~mA} \mathrm{~h} \mathrm{~g}^{-1}\right)$. As a result, the coulombic efficiency (CE) is $98.2 \%$. As can be seen from the figure 10 , the specific capacity of nano-composite has been maintained at about $850 \mathrm{mAh} \cdot \mathrm{g}^{-1}$ after 10 cycles. As the number of cycles is added, the capacity decreases further.

The initial discharge curve shows lengthy flat tail with a plateau. It can be related to the delithiation from amorphous $\mathrm{Li}_{\mathrm{X}} \mathrm{Si}$ phase. The CE stabilized at $95 \%$ to $98 \%$ for next 10 remaining cycles. In the first lithiation cycle, a voltage drop slope can be seen approximately in the range $1.0-0.2 \mathrm{~V}$. It is due to the SEI film development. In the discharge curves a sloping platform between 0.2 and $0.01 \mathrm{~V}$ is specified, that is consistent with the lithiation of $\mathrm{Si}$ to $\mathrm{Li}_{\mathrm{x}} \mathrm{Si}$.

In Figure 11 the cycling performance of Si NPs-rGO nanonano-composite, prinstine Si NPs [63] and rGO [64] has been compared at a current density of $100 \mathrm{mAg}^{-1}$. As can be seen the Si NPs show a rapid capacity fading from $\otimes 1990$ to $\otimes 164 \mathrm{mAh} \mathrm{g}^{-1}$ after 11 cycles, rGO a capacity fading with gentle and gradual slope from $\otimes 451$ to $\otimes 175 \mathrm{mAh} \mathrm{g}^{-1}$, while the SiNPs- rGO nanonano-composites show capacity fading from 1212 to $843 \mathrm{~mA} \mathrm{~h} \mathrm{~g}^{-1}$ After this number of cycles.

The rGO represent better reversibility than the Si NPs while the reversible capacity and initial CE is relatively low.

The initial coulombic efficiency and capacity retention of the Si NPs-rGO anode shows significant improvement over $\mathrm{Si}$ and $\mathrm{rGO}$ anode. This can be attributed to the role of graphene layers in improving the cyclic performance due to the increase in electrical conductivity and stabilization of the nanocomposite structure. 
The decay of reversible capacity of the Si NPs-rGO over 10 cycles can result from the pulverization of Si nanoparticles during lithiation/delithiation, leads to the gradual damage of the intimate attachment between the Si nanoparticles and graphene and the missing the electrical connectivity between them.

\section{Conclusion}

In summary, the SiNPs-rGO nano-composite using the CTAB surfactant was successfully synthesized by thermal reduction. The FTIR, XRD and FESEM analysis confirm the nano-composite formation. The test of anode electrode sample carried out by potential $\left(\mathrm{Li} / \mathrm{Li}^{+}\right)$vs. capacity measurements. A suitable specific capacity of $845 \mathrm{mAhg}^{-1}$ after 10 cycles at current density of $100 \mathrm{mAg}^{-1}$ and coulomb efficiency of approximately $99.4 \%$ was obtained. This high capacity of SiNPs-rGO to the role of porous $\mathrm{Si}$ nanoparticles which facilitate electron transfer and high surface area and conductivity of graphene sheets. Additional studies using nano-composites of silicon nanostructures and carbon derivatives to improve cyclic performance are ongoing in our laboratory.

\section{Declarations}

\section{Declaration of interests}

The authors declare that they have no known competing financial interests or personal relationships that could have appeared to influence the work reported in this paper.

Conflict of Interest: The authors declare that they have no conflict of interest.

Copyright rules and Ethics: The authors have agreement with all the copyright rules and ethics in publishing that could have appeared to influence the work reported in this paper.

\section{References}

1. Li, H.; Huang, X.; Chen, L.; Wu, Z.; Liang, Y. A high-capacity nano Si nano-composite anode material for lithium rechargeable batteries. Electrochem. Solid-State Lett. 1999, 2, 547-549.

2. Weydanz, W., Wohlfahrt-Mehrens, M.; Huggins, R.A. A room temperature study of the binary lithiumsilicon and the ternary lithium-chromium-silicon system for use in rechargeable lithium batteries. J. Power Sources, 1999, 81, 237-242.

3. F. Luo, B. Liu, J. Zheng, G. Chu, K. Zhong, H. Li, X. Huang, L. Chen, Reviewd nano-silicon/carbon nanocomposite anode materials towards practical application for next generation Li-ion batteries, J. Electrochem. Soc. 162 (2015) A2509eA2528.

4. K. Feng, M. Li, W. Liu, A.G. Kashkooli, X. Xiao, M. Cai, Z. Chen, Silicon-based anodes for lithium-ion batteries: from fundamentals to practical applications, Small 14 (2018) 1702737.

5. Current Progress of Si/Graphene nano-composites for Lithium-Ion Batteries, Yinjie Cen 
6. Silicon-based anodes for lithium-ion batteries: Effectiveness of materials synthesis and electrode preparation, Anix Casimir

7. Bian, J. Yu, W. Song, H. Huang, C. Liang, Y. Gan, Y. Xia, J. Zhang, X. He, Zhang, A new magnesium hydride route to synthesize morphology-controlled $\mathrm{Si} / \mathrm{rGO}$ nano-composite towards highperformance lithium storage

8. Subrahmanyam Goriparti, Ermanno Miele, Francesco De Angelis, Enzo Di Fabrizio, Remo Proietti Zaccaria, Claudio Capiglia, Review on recent progress of nanostructured anode materials for Li-ion batteries, Journal of Power Sources 257 (2014) 421e443, http://dx.doi.org/10.1016/j.jpowsour.2013.11.103

9. Romeo Malik, Qianye Huang, Laura Silvestri, Danqing Liu, Vittorio Pellegrini, et.al, Synthesis of layered silicon-graphene hetero-structures by wet jet milling for high-capacity anodes in Li-ion batteries, 2D Mater.8(2021) 015012https://doi.org/10.1088/2053-1583/aba5ca

10. H. Dong, X. Fu, J. Wang, P. Wang, H. Ding, R. Song, S. Wang, R. Li, S. Li,In-situ construction of porous Si@C nano-composites with LiCl template to provide silicon anode expansion buffer, Carbon, https://doi.org/10.1016/j.carbon.2020.11.042.

11. H. Xu, Y. Wang, R. Chen, Y. Bai, T. Li, H. Jin, J. Wang, H. Xia, A green-synthetic spiderweb-like Si@Graphene-Oxide anode material with multifunctional citric acid binder for high energy-density Liion batteries, Carbon (2019), doi: https://doi.org/10.1016/j.carbon.2019.10.046

12. J.P. Maranchi, A.F. Hepp, A.G. Evans, N.T. Nuhfer, P.N. Kumta, Interfacial Properties of the a-Si/Cu: Active-Inactive Thin-Film Anode System for Lithium-lon Batteries, J. Electrochem. Soc. 153 (2006) A1246.

13. Lu, J.; Chen, Z.; Pan, F.; Cui, Y.; Amine, K., High-performance anode materials for rechargeable lithiumion batteries. Electrochemical Energy Reviews 2018,1(1), 35-53.

14. Zhang, L.; Wang, C.; Dou, Y.; Cheng, N.; Cui, D.; Du, Y.; Liu, P.; Al-Mamun, M.; Zhang, S.; Zhao, H., A YolkShell Structured Silicon Anode with Superior Conductivity and High Tap Density for Full Lithium-lon Batteries. Angewandte Chemie International Edition 2019,58(26), 8824-8828.

15. Huang, X.; Sui, X.; Yang, H.; Ren, R.; Wu, Y.; Guo, X.; Chen, J., HF-free synthesis of Si/C yolk/shell anodes for lithium-ion batteries. Journal of Materials Chemistry A 2018,6(6), 2593-2599

16. liangming Wei, Zhongyu Hou, Hao Wei, Porous Sandwiched Graphene/Silicon Anodes for Lithium Storage, Electrochimica Actahttp://dx.doi.org/10.1016/j.electacta.2017.01.173

17. Kaifeng Yu, Hanxiang Zhang, Hui Qi, Jicai Liangand Ce Liang, High performance of porous silicon/carbon/RGO network derived from rice husks as anodes for lithium-ion batteries, New J.Chem.,2018,42,19811, DOI: 10.1039/c8nj05098h

18. Liangming Wei, Zhongyu Hou, Hao Wei, Porous Sandwiched Graphene/Silicon Anodes for Lithium Storage, Electrochimica Actahttp://dx.doi.org/10.1016/j.electacta.2017.01.173

19. Alexander A. Balandin, Phononics of Graphene and Related Materials, ACS Nano 2020, 14, 5, 51705178, https://doi.org/10.1021/acsnano.0c02718 
20. J. Wang, J. Song, X. Mu, M. Sun, Optoelectronic and photoelectric properties and applications of graphene-based nanostructures, Materials Today Physics Volume 13, June 2020, 100196, https://doi.org/10.1016/j.mtphys.2020.100196

21. Muge Acik, Yves J. Chabal, A Review on Thermal Exfoliation of Graphene Oxide, Journal of Materials Science Research; Vol. 2, No. 1; 2013, doi:10.5539/jmsr. v2n1p101

22. Sh. Maharubin, M. X. Zhang, F. Zhu, H-C. Zhang, G. Zhang, Y. Zhang, Synthesis and Applications of Semiconducting Graphene, J. Nanomaterials, Volume 2016, Article ID 6375962, 19, pages, http://dx.doi.org/10.1155/2016/6375962

23. J. Park, Y. Kim, S.Y. Park, S.J. Sung, H.W. Jang, C.R. Park, Band gap engineering of graphene oxide for ultrasensitive NO2 gas sensing, Carbon (2020), doi: https://doi.org/10.1016/j.carbon.2019.11.063

24. Tao Meng, Bo Li, Lei Hu, Hao Yang, Wenjie Fan et.al, Engineering of Oxygen Vacancy and Electric Field Effect by Encapsulating Lithium Titanate in Reduced Graphene Oxide for Superior Lithium Ion Storage, Small Methods, DOI: 10.1002/smtd.201900185

25. Seokhoon Choi, Changyeon Kim, Jun Min Suh, Ho Won Jang, Reduced graphene oxide-based materials for electrochemical energy conversion reactions, Carbon Energy. 2019; 1:85-108, DOI: $10.1002 /$ cey 2.13

26. Yibo Yan, Jun Gong, Jie Chen, Zhiping Zeng, Wei Huang et.al, Recent Advances on Graphene Quantum Dots: From Chemistry and Physics to Applications, Adv.Mater.2019, 1808283, DOI: 10.1002/adma.201808283

27. Acik, M. and Chabal1, Y. J., "A Review on Reducing Graphene Oxide for Band Gap Engineering”, J. Mater. Sci. Res., 2013, 2 (1), 101-111.

28. Neeraj Sharmaa, Mohd. Arifa, Shagun Mongaa, Mohd. Shkirb, Yogendra K. Mishrac, Arun Singh, Investigation of bandgap alteration in graphene oxide with different reduction routes, Applied Surface Science 513 (2020) 145396, https://doi.org/10.1016/j.apsusc.2020.145396

29. S. Mao, Z. Wen, H. Kim, G. Lu, P. Hurley and J. Chen, ACS Nano, 2012,6, 7505-7513.

30. Chang, H. et al. Regulating infrared photo responses in reduced graphene oxide phototransistors by defect and atomic structure control. ACS Nano. 7, 6310-6320 (2013

31. Chien, C. T. et al. Tunable photoluminescence from graphene oxide. Angewandte Chemie International Edition. 51, 6662-6666 (2012).

32. Sh. Maharubin, M. X. Zhang, F. Zhu, H-C. Zhang, G. Zhang, Y. Zhang, Synthesis and Applications of Semiconducting Graphene, J. Nanomaterials, Volume 2016, Article ID 6375962, 19 pages, http://dx.doi.org/10.1155/2016/6375962.

33. H. Tang, J. Zhang, Y.J. Zhang, Q.Q. Xiong, Y.Y. Tonga et.al., Porous reduced graphene oxide sheet wrapped silicon nano-composite fabricated by steam etching for lithium-ion battery application, Journal of Power Sources 286 (2015) 431e437, http://dx.doi.org/10.1016/j.jpowsour.2015.03.185.

34. J. Chang, X. Huang, G. Zhou, Sh. Cui, P. B. Hallac .et. al, Multilayered Si Nanoparticle/Reduced Graphene Oxide Hybrid as a High-Performance Lithium-Ion Battery Anode, Adv. Mater, DOI: 10.1002/adma.201302757. 
35. S.F.A. Shattar, N.A. Zakaria \& K.Y. Foo (2016) "Feasibility of montmorillonite- assisted adsorption process for the effective treatment of organo-pesticides", Desalination and Water Treatment, 57:29, 13645-13677, DOI: 10.1080/19443994.2015.1065439.

36. Y. S. He, P. Gao, J. Chen, X. Yang, X. Z. Liao, J. Yang and Z. F. Ma )2011(, "A novel bath lily-like graphene sheet-wrapped nano-Si nano-composite as a high performance anode material for Li-ion batteries" , RSC Adv., 1, 958-960.

37. X. Zhou, Y. X. Yin, L. J. Wan and Y. G. Guo, )2012("Facile synthesis of silicon nanoparticles inserted into graphene sheets as improved anode materials for lithium-ion batteries",Chem. Commun., 48, 2198-2200.

38. F. Maroni, R. Raccichini, A. Birrozzi, G. Carbonari, R. Tossici, F. Croce, R. Marassi and F. Nobili)2014(, "Graphene/silicon nano-composite anode with enhanced electrochemical stability for lithium-ion battery applications", J. Power Sources, 269, 873-882.

39. Y. Chen, X. Zhang, Y. Tian and X. Zhao)2014(, "Synthesis and Characterization of Silicon Nanoparticles Inserted into Graphene Sheets as High-Performance Anode Material for Lithium Ion Batteries", J. Nanomater., 734751.

40. H. Xiang, K. Zhang, G. Ji, J. Y. Lee, C. Zou, X. Chen and J. Wu)2011(, "Graphene/nanosized silicon nano-composites for lithium battery anodes with improved cycling stability", Carbon, 49, 1787-1796.

41. S. Yang, G. Li, Q. Zhu and Q. Pan)2012(, "Covalent binding of Si nanoparticles to graphene sheets and its influence on lithium storage properties of Si negative electrode", J. Mater. Chem., 22, 34203425.

42. Yifan Chen, Ning Du, Hui Zhang and Deren Yang, Firmly bonded graphene-silicon nano-composites as high-performance anode materials for lithium-ion batteries, RSC Adv.2015,5, 46173, DOI: $10.1039 / \mathrm{c} 5 \mathrm{ra05869d}$.

43. W. Sun, R. Hu, H. Liua, M. Zenga, L. Yang, H. Wang and M. Zhu, Embedding nano-silicon in graphene nanosheets by plasma assisted milling for high capacity anode materials in lithium ion batteries, $\mathrm{J}$. Power Source, 2014,268, 610-618, doi.org/10.1016/j.jpowsour.2014.06.039

44. Y. Du, G. Zhu, K. Wang, Y. Wang, C. Wang, Y. Xia, Si/graphene nano-composite prepared by magnesium thermal reduction of $\mathrm{SiO}_{2}$ as anode material for lithium-ion batteries, Electrochemistry Communications (2013), doi: 10.1016/j.elecom.2013.09.019.

45. F. Bian, J. Yu, W. Song, H.Huang, C.Liang, et.al., A new magnesium hydride route to synthesize morphology-controlled $\mathrm{Si} / \mathrm{rGO}$ nano-composite towards high-performance lithium storage, Electrochimica Acta, Volume 330, 2020, 135248, https://doi.org/10.1016/j.electacta.2019.135248.

46. X. Li, M. Zhang, Sh. Y. Ch. Lu, Research Progress of Silicon/Carbon Anode Materials for Lithium-lon Batteries: Structure Design and Synthesis Method, Chem ElectroChem 10.1002/celc.202001060.

47. H. Torkashvand, M. M. Bagheri-Mohagheghi, The effect of stoichiometric ratio of $\mathrm{Mg} / \mathrm{SiO}_{2}$ and annealing on physical properties of silicon nanoparticles by magnesium-thermic chemical reduction process using the $\mathrm{SiO}_{2}$ precursor, Applied Physics A (2020) 126:51 https://doi.org/10.1007/s00339019-3223-3. 
48. Mingyuan Ge, Jiepeng Rong, Xin Fang, Anyi Zhang, Yunhao Lu, et al. (2013), "Scalable preparation of porous silicon nanoparticles and their application for lithium-ion battery anodes", Nano Research, 6(3): 174-181, DOI 10.1007/s12274-013-0293-y.

49. Lili Wu, Juan Yang, Jingjing Tang, Yongpeng Ren, Yang Nie, Xiangyang Zhou, (2016). "Threedimensional graphene nanosheets loaded with $\mathrm{Si}$ nanoparticles by in situ reduction of $\mathrm{SiO}_{2}$ for lithium ion batteries", Electrochimica Acta 190, 628-635, http://dx.doi.org/10.1016/j.electacta.2015.12.192.

50. Baoqin Guan, Yu Sun, Xiaopeng Li, Junna Wang, Si Chen, Stefan Schweizer, Yong Wang, and Ralf B. Wehrspohn," Conversion of Bulk Metallurgical Silicon into Photocatalytic Nanoparticles by CopperAssisted Chemical Etching", ACS Sustainable Chem. Eng, DOI: 10.1021/acssuschemeng.6b01481.

51. Yifan Chen, Ning Du, Hui Zhang, Deren Yang, )2015(. "Firmly bonded graphene-silicon nanocomposites as high-performance anode materials for lithium-ion batteries", RSC Adv.,5, 46173-46180, doi.org/10.1039/C5RA05869D.

52. F. Bian, J. Yu, W. Song, H. Huang, C. Liang, Y. Gan, Y. Xia, J. Zhang, X. He, W. Zhang, )2019(. "A new magnesium hydride route to synthesize morphology-controlled $\mathrm{Si} / \mathrm{rGO}$ nano-composite towards highperformance lithium storage", Electrochimica Acta, doi: https://doi.org/10.1016/ electacta.135248.

53. Marcano D C, Kosynkin D V, Berlin J M, Improved Synthesis of Graphene Oxide, ACS NANO, 2010, 4, 4806-4814. https://doi.org/10.1021/nn1006368.

54. H. Xu, Y. Wang, R. Chen, Y. Bai, T. Li, H. Jin, J. Wang, H. Xia, A green-synthetic spiderweb-like Si@Graphene-oxide anode material with multifunctional citric acid binder for high energy-density Liion batteries, Carbon (2019), doi: https://doi.org/10.1016/j.carbon.2019.10.046.

55. Song J, Zhou M, Yi R, Advanced Functional Materials, 2015, 24, 5904-5910.

56. Zhu, J., Ren, Y., Yang, B. et al. Embedded Si/Graphene Nano-composite Fabricated by MagnesiumThermal Reduction as Anode Material for Lithium-Ion Batteries. Nanoscale Res Lett 12, 627 (2017). https://doi.org/10.1186/s11671-017-2400-6.

57. Cheng Sun, Yuanfu Deng, Lina Wan, Xusong Qin and Guohua Chen, Graphene Oxide-Immobilized NH2-Terminated Silicon Nanoparticles by Cross-Linked Interactions for Highly Stable Silicon Negative Electrodes, ACS Appl. Mater. Interfaces. 2014, 6, 11277-11285, doi.org/10.1021/am502597g.

58. Ch. Shan, K. Wu,H. Yen, C.N Villarrubia, T. Nakotte, Graphene Oxides Used as a New“ Dual Role" Binder for Stabilizing Silicon Nanoparticles in Lithium-lon Battery, ACS Appl. Mater. Interfaces 2018, 10, 15665-15672, DOI:10.1021/acsami.8b00649.

59. Emiru, T. F., \& Ayele, D. W. (2017). Controlled synthesis, characterization and reduction of graphene oxide: A convenient method for large scale production. Egyptian Journal of Basic and Applied Sciences, 4(1), 74-79. doi: 10.1016/j.ejbas.2016.11.002.

60. Michael Schmitt, Synthesis and testing of $\mathrm{ZnO}$ nanoparticles for photo-initiation: Experimental observation of two different non-migration initiators fr bulk polymerization, April 2015, Nanoscale 7(21), DOI: 10.1039/C5NR00850F. 
61. V. Sharova, A. Moretti, G. A. Giffin, D. V. Carvalho, and S. Passerini, "Evaluation of Carbon-Coated Graphite as a Negative Electrode Material for Li-lon Batteries," C, vol. 3, no. 3, p. 22, 2017.

62. J. J. Wu and W. R. Bennett, "Fundamental investigation of Si anode in Li-ion cells," in Energytech, 2012 IEEE, 2012, pp. 1-5: IEEE.

63. Facile synthesis of uniform MWCNT@Si nano-composites as high-performance anode materials for lithium-ion batteries, Yifan Chen, Ning Du, Hui Zhang, Deren Yang, Journal of Alloys and Compounds 622 (2015) 966-972, http://dx.doi.org/10.1016/j.jallcom.2014.11.032.

64. Firmly bonded graphene-silicon nano-composites as high-performance anode materials for lithiumion batteries, Yifan Chen, Ning Du, ${ }^{\star}$ Hui Zhang and Deren Yang , RSC Adv., 2015, 5, 46173, DOI: $10.1039 /$ c5ra05869d.

\section{Table}

Table 1. Weight percent of elements in Si NPs- rGO nano-composite.

\begin{tabular}{|ll|}
\hline Element & Weight\% \\
$\mathrm{C}$ & 54.93 \\
$\mathrm{O}$ & 25.37 \\
$\mathrm{Si}$ & 15.56 \\
$\mathrm{Mg}$ & 1.31 \\
$\mathrm{Al}$ & 1.86 \\
$\mathrm{Na}$ & 0.96 \\
$\mathrm{Ca}$ & 0.01 \\
\hline
\end{tabular}

\section{Figures}



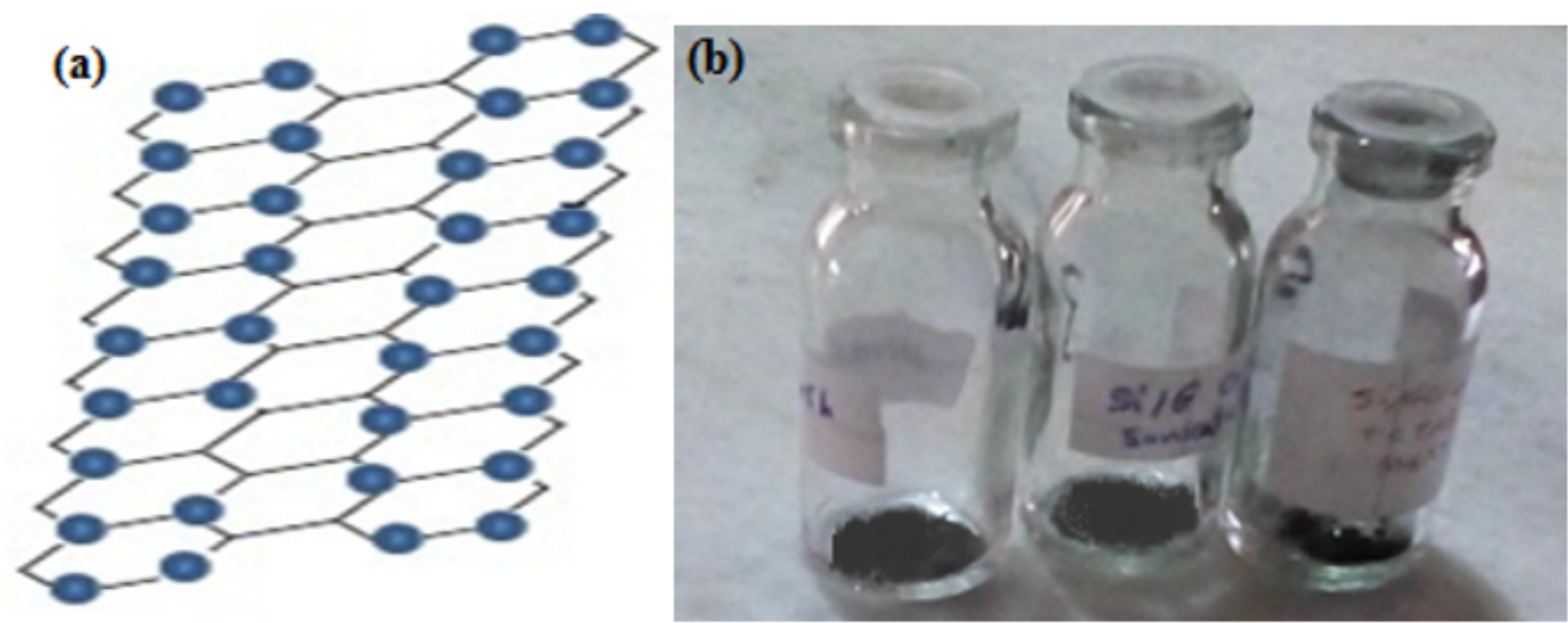

Figure 1

(a) Schematic view of the SiNPs-rGO nano-composite network structure. (b) Samples of synthesized SiNp-rGO nano-composites.

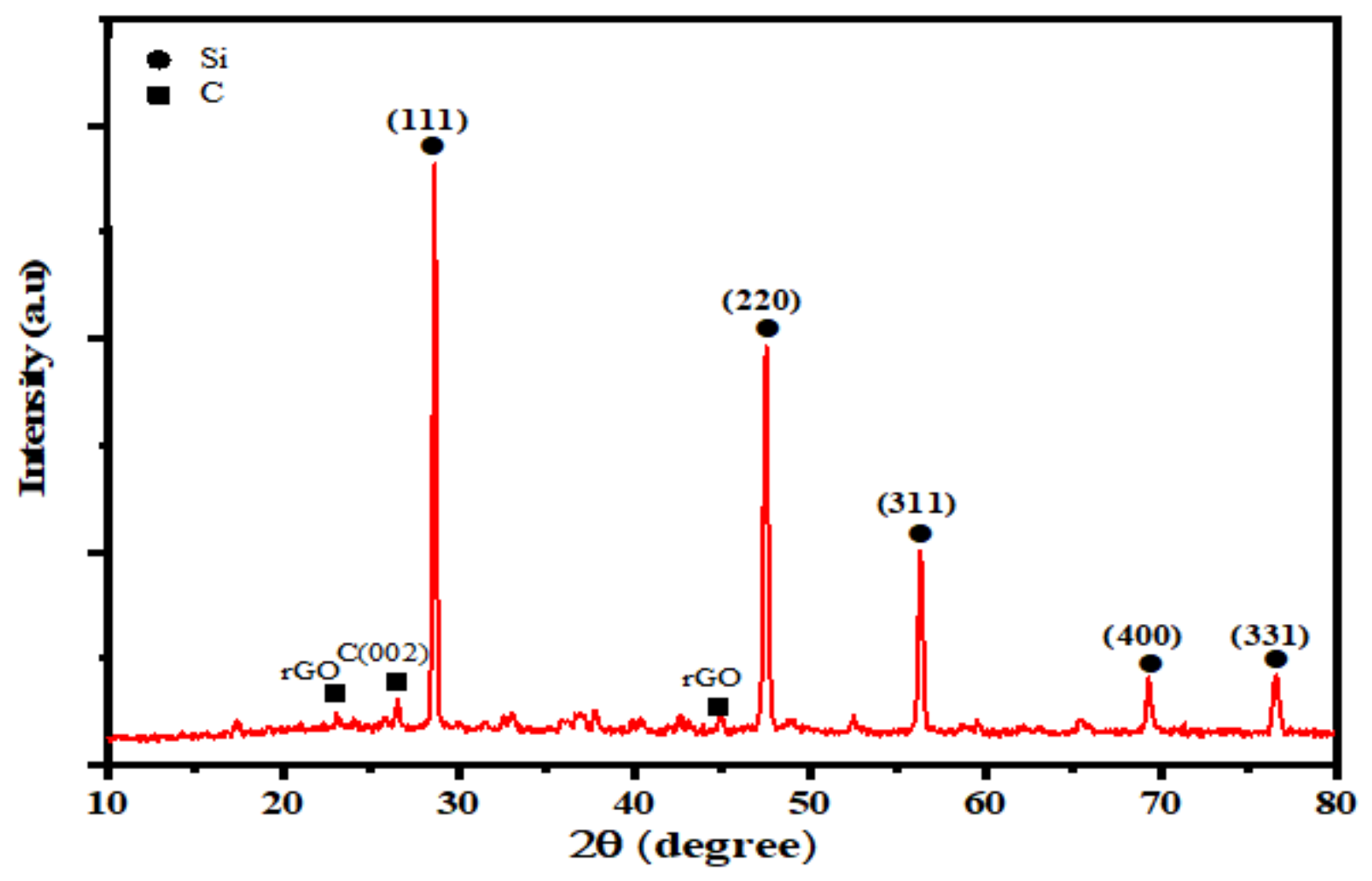

Figure 2

The XRD pattern of Si NPs- rGO nano-composite for Synthesis1 with CTAB. 


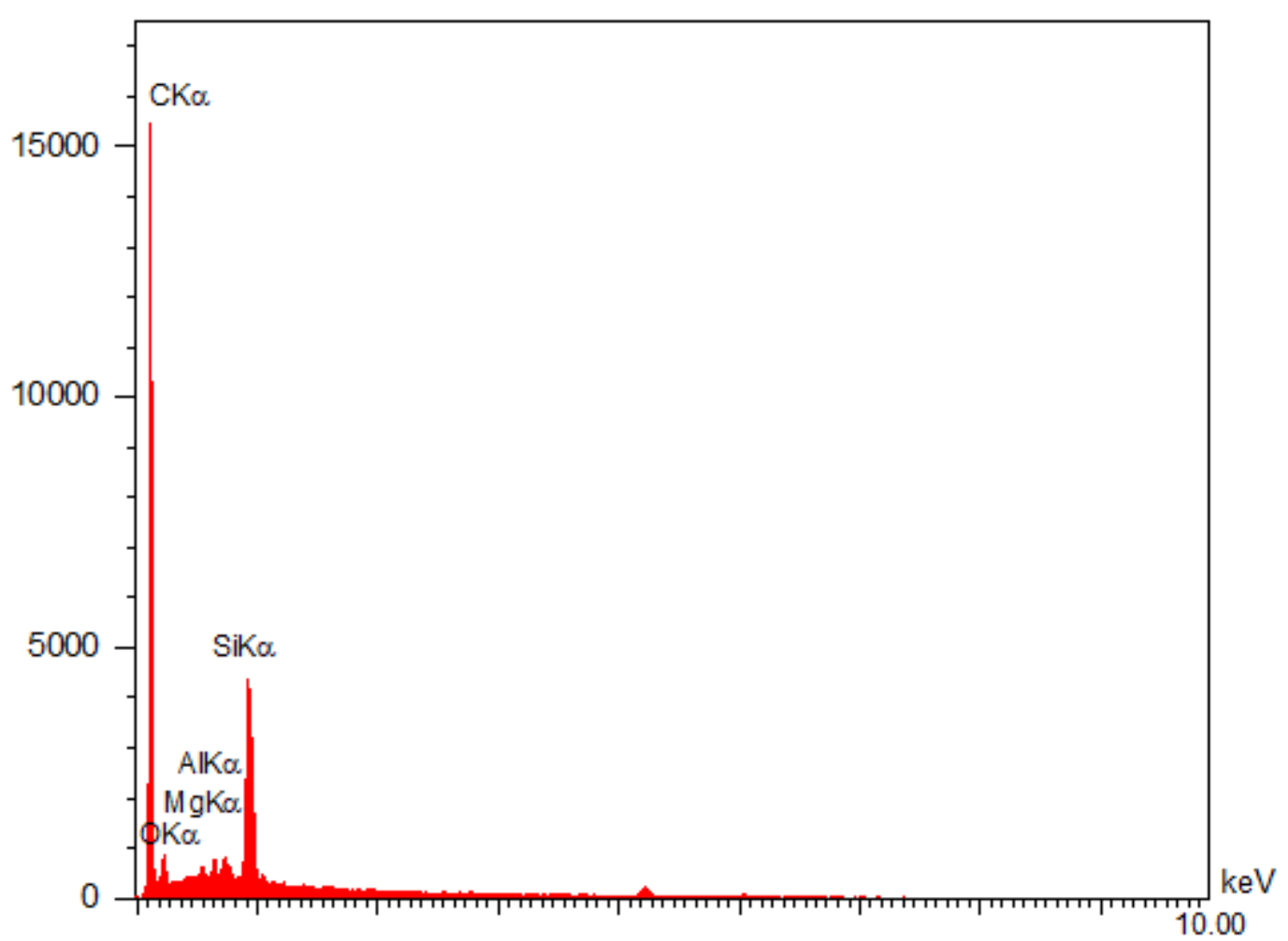

Figure 3

EDX spectrum corresponding to Si NPs- rGO nano-composite for Synthesis1 with CTAB. 

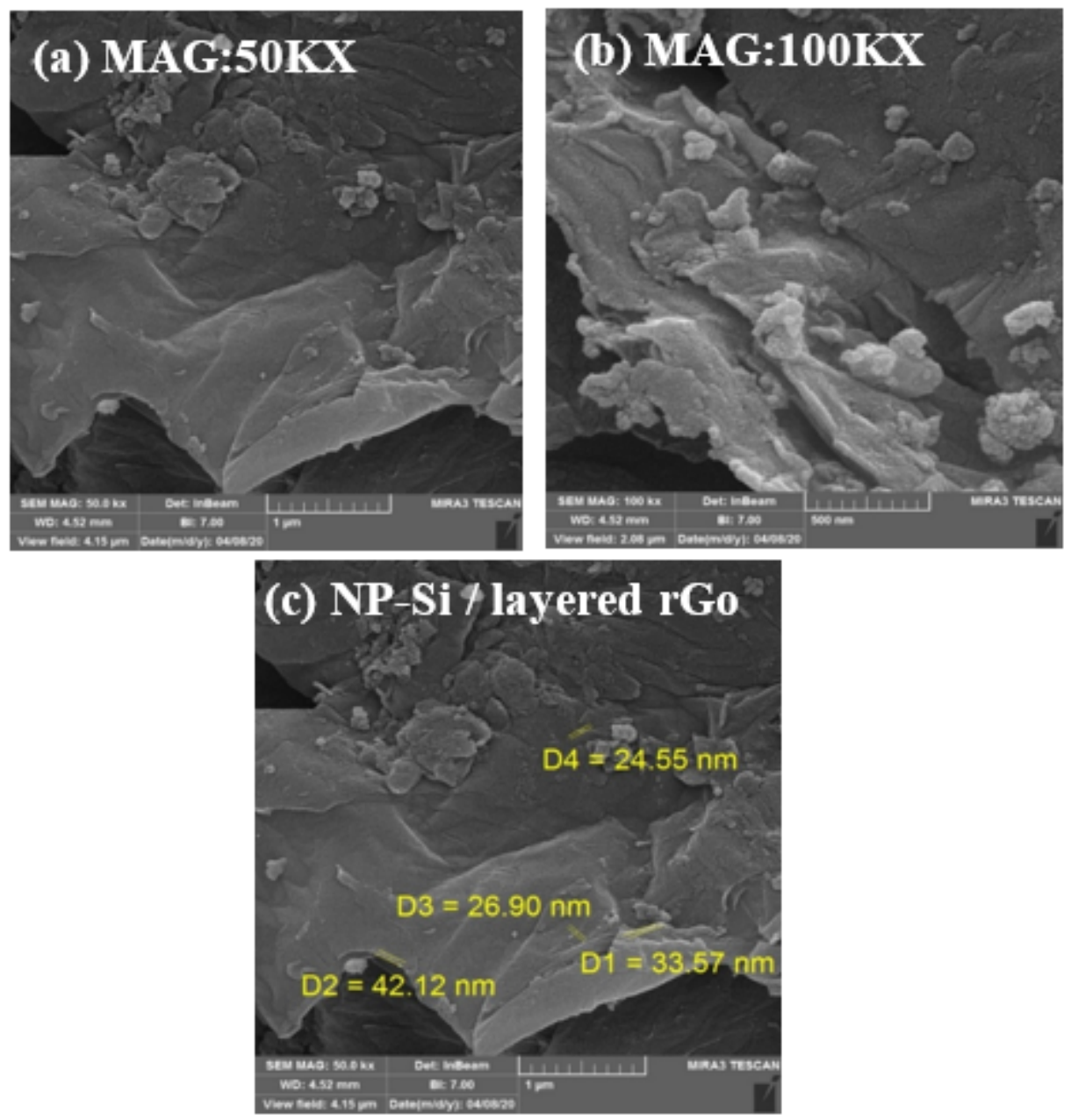

\section{Figure 4}

(a) to (c) FESEM image of Si NPs- rGO nano-composite in synthesis 1 using CTAB surfactant at Magnification: $50 \mathrm{KX}$ and $100 \mathrm{KX}$. 

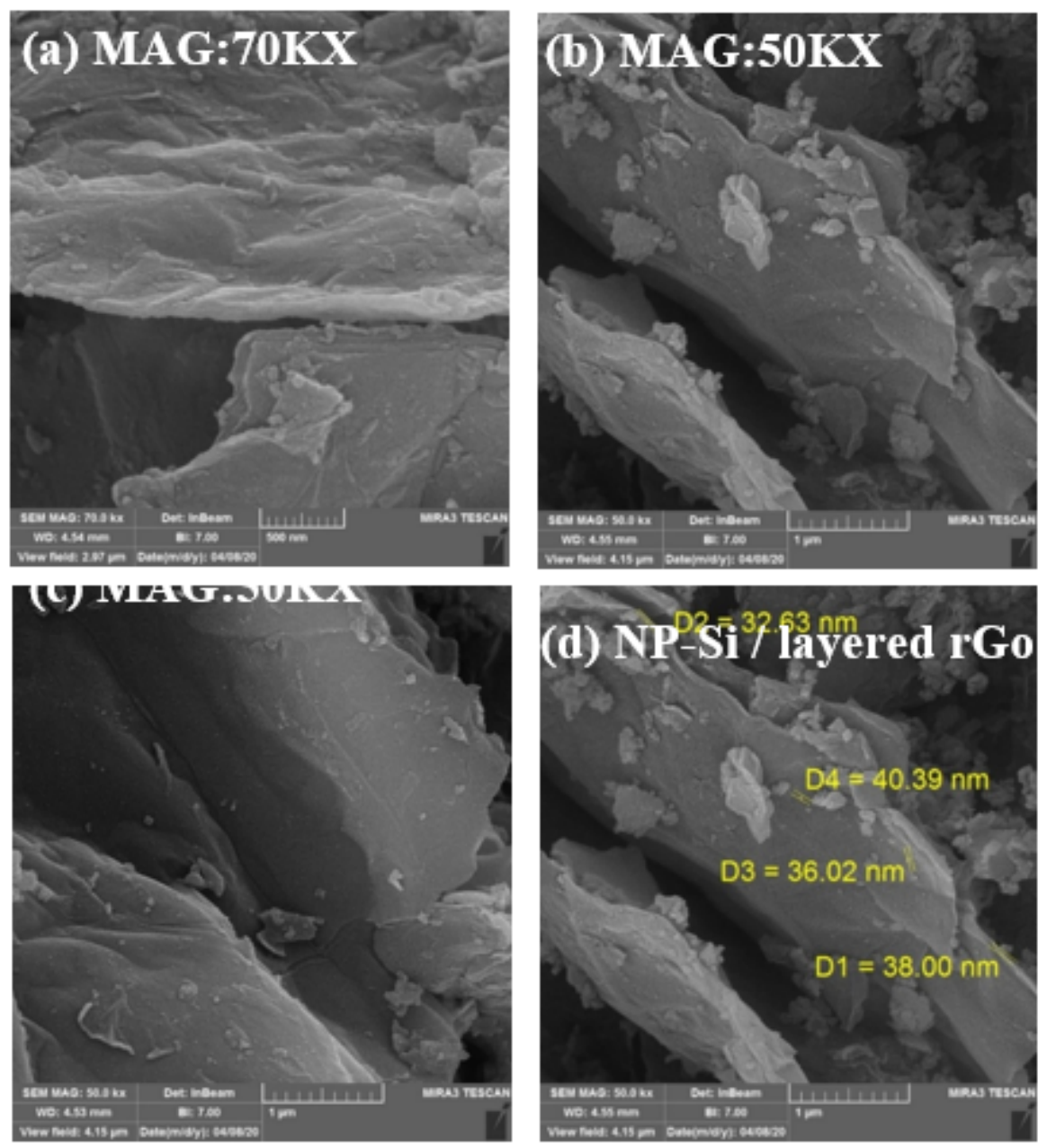

\section{Figure 5}

(a) to (d) FESEM image of Si NPs- rGO nano-composite in synthesis 2 using CTAB and citric acid.

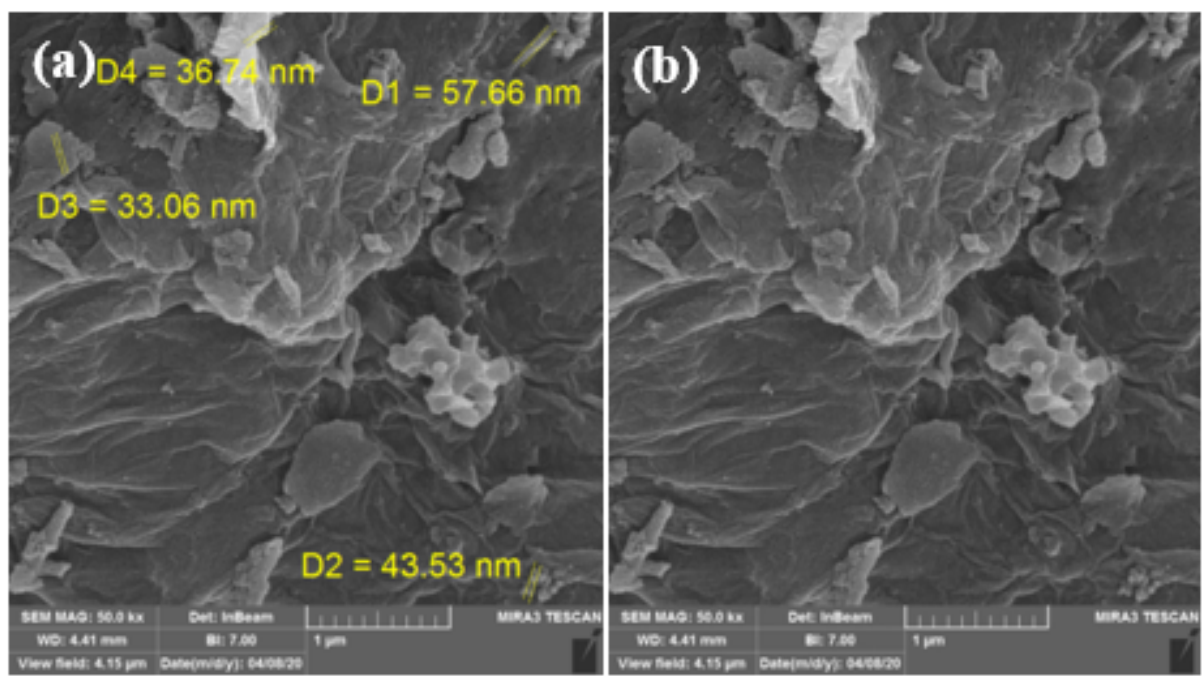

\section{Figure 6}

(a) and (b) FE-SEM image of Si NPs- rGO nano-composite in synthesis 3 by Citrate with ultrasonic. 

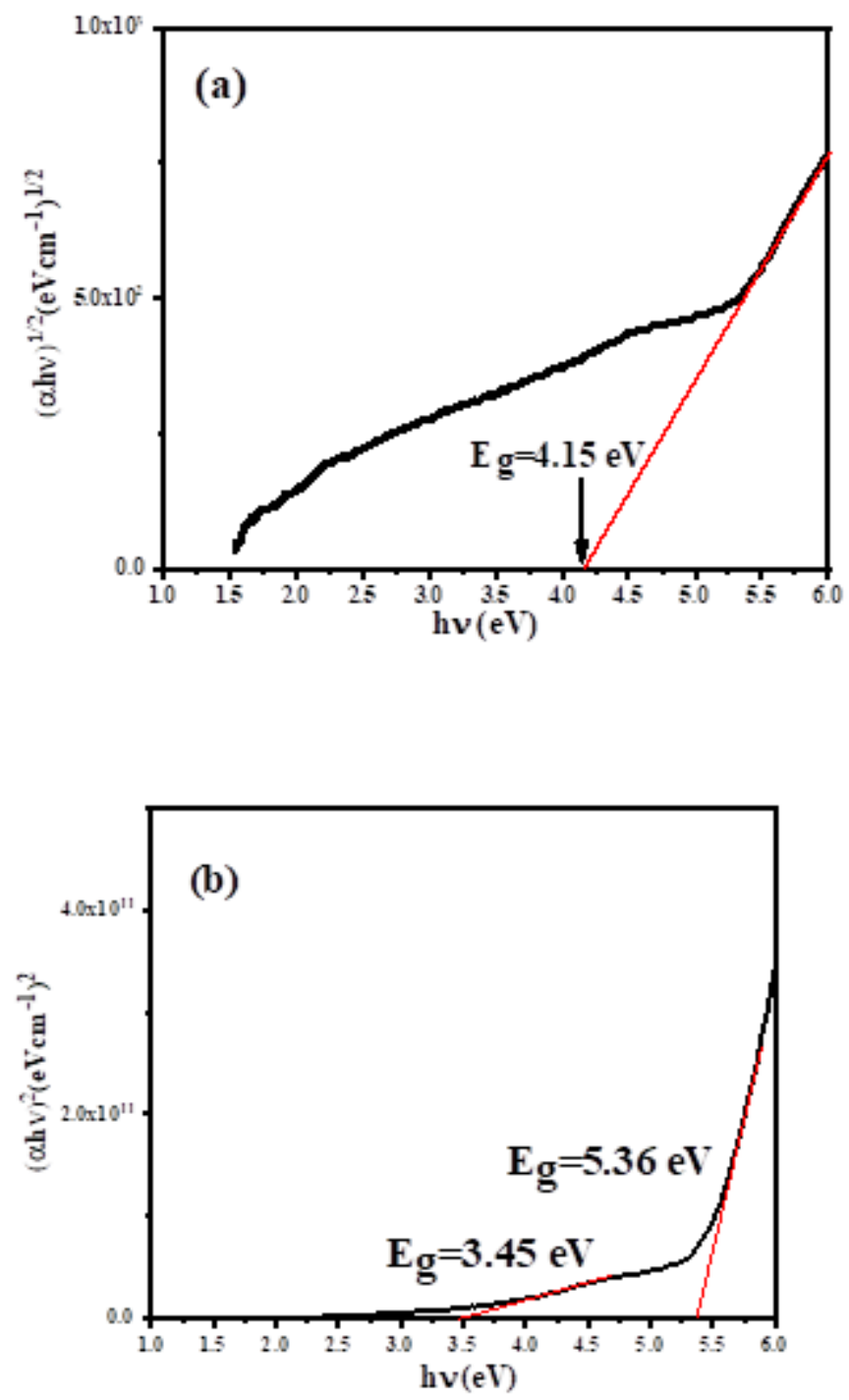

Figure 7

(a) Diagram of (ahu) $1 / 2$ for indirect band gap and (b) (ahu) 2 for direct band gap in term of h区 for Synthsis1. 


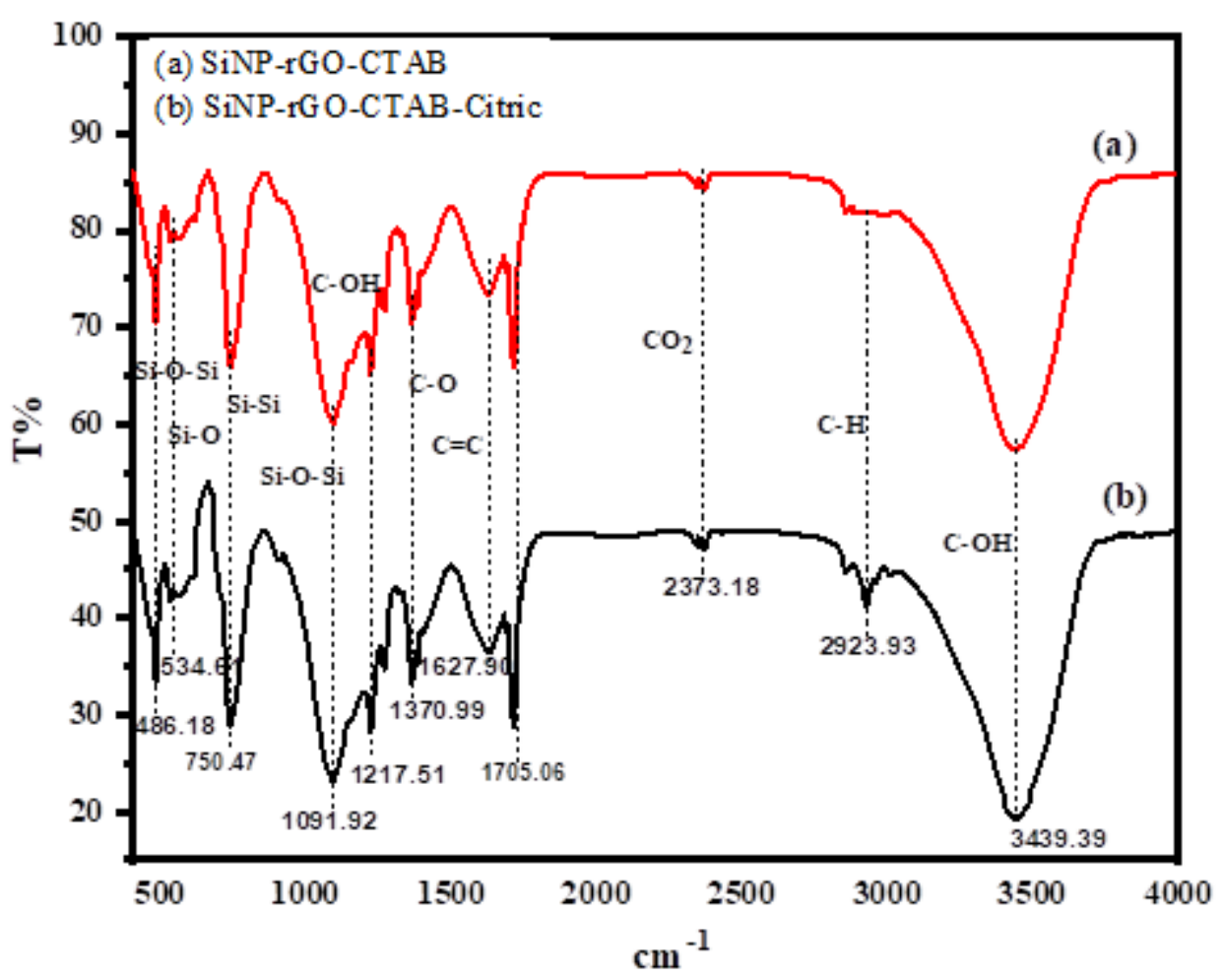

Figure 8

FTIR spectra of (a) Synthesis 1: SiNP-rGO-CTAB and (b) Synthesis 2: SiNP-rGO-CTAB-Acid Citric nanocomposites. 

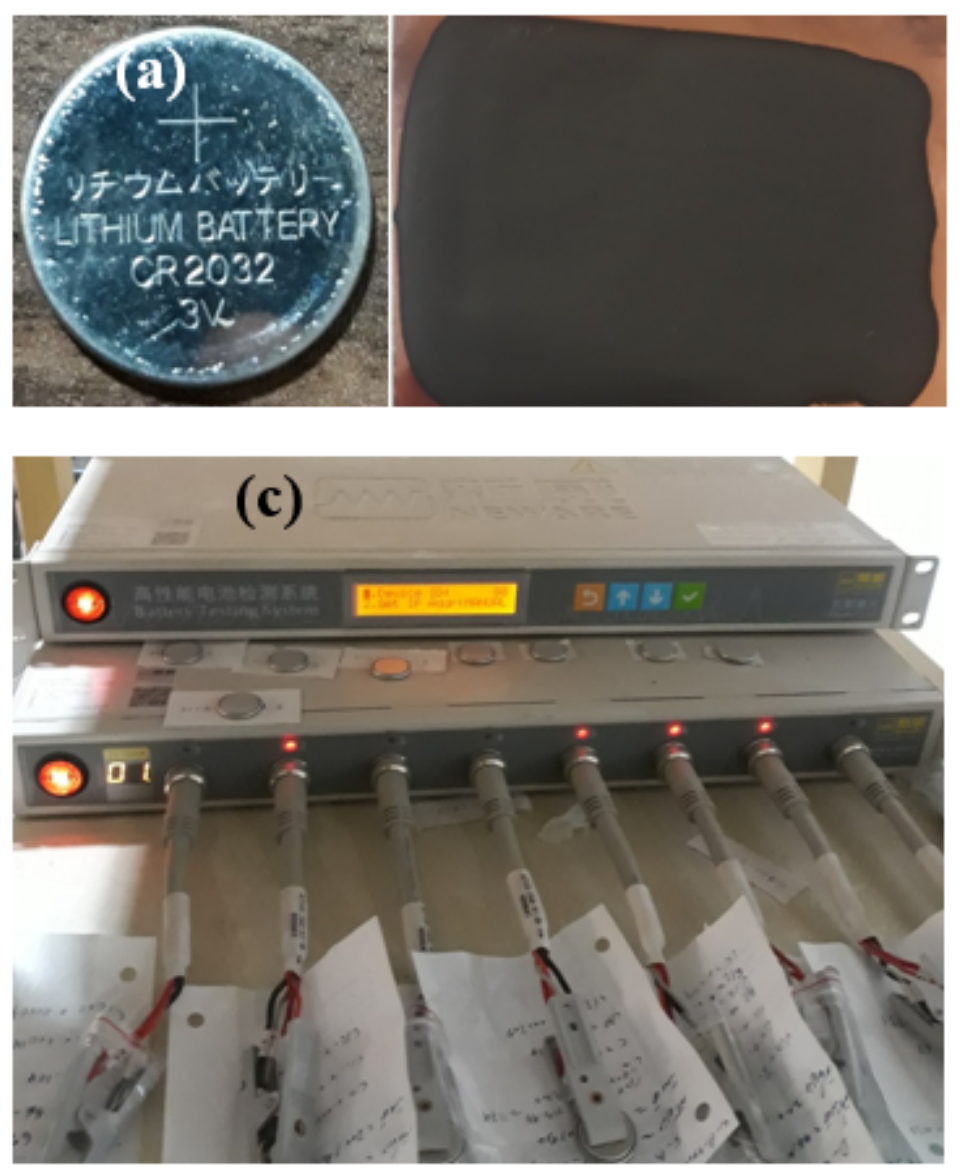

\section{Figure 9}

(a) Anode electrode sample for Synthesis 1, with CTAB after drying (b) Coin cell battery sample (c) Battery tester. 


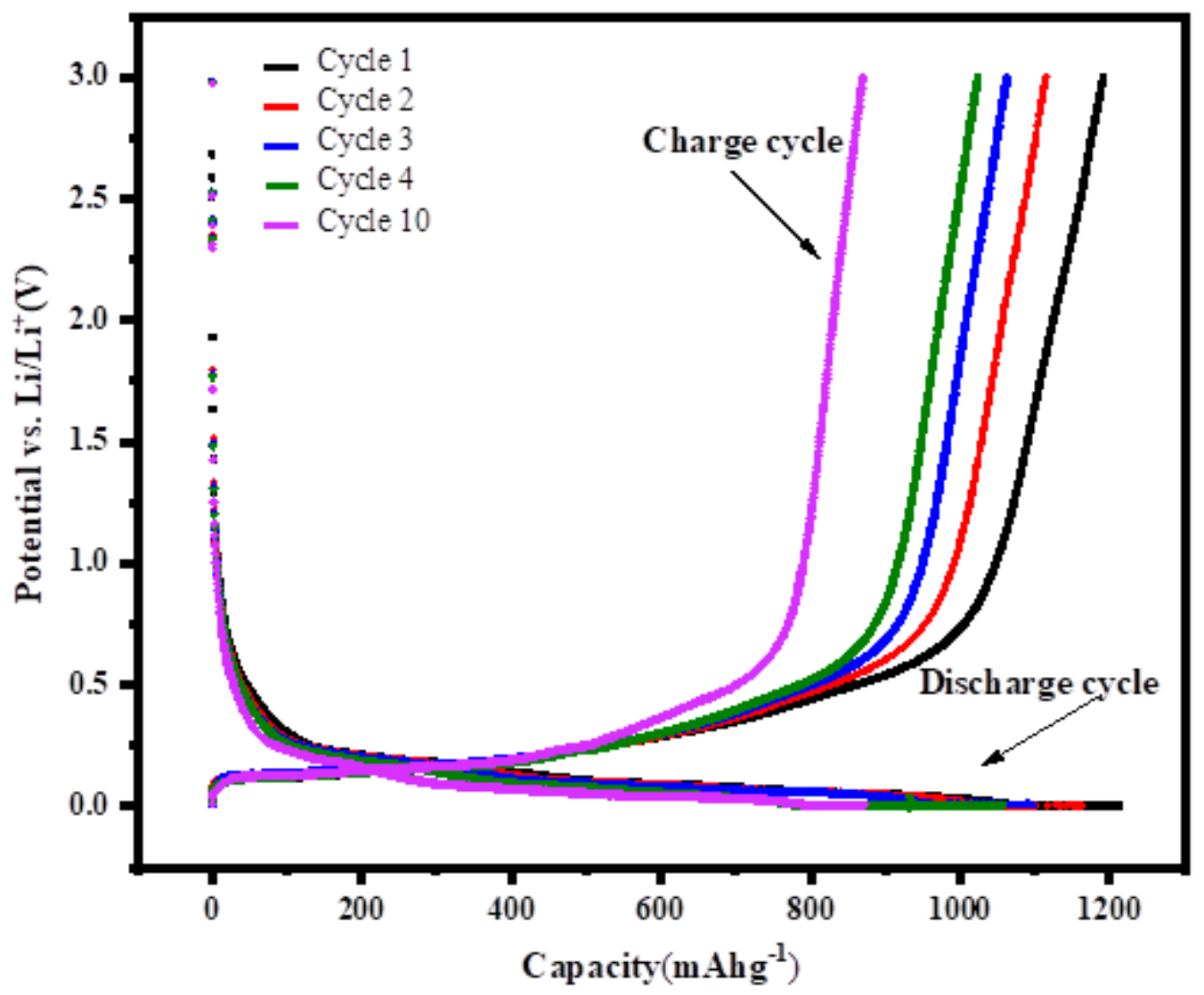

Figure 10

Voltage-Capacity profiles of Si NPs-rGO nano-composite anode for different cycles for Synthesis 1. 


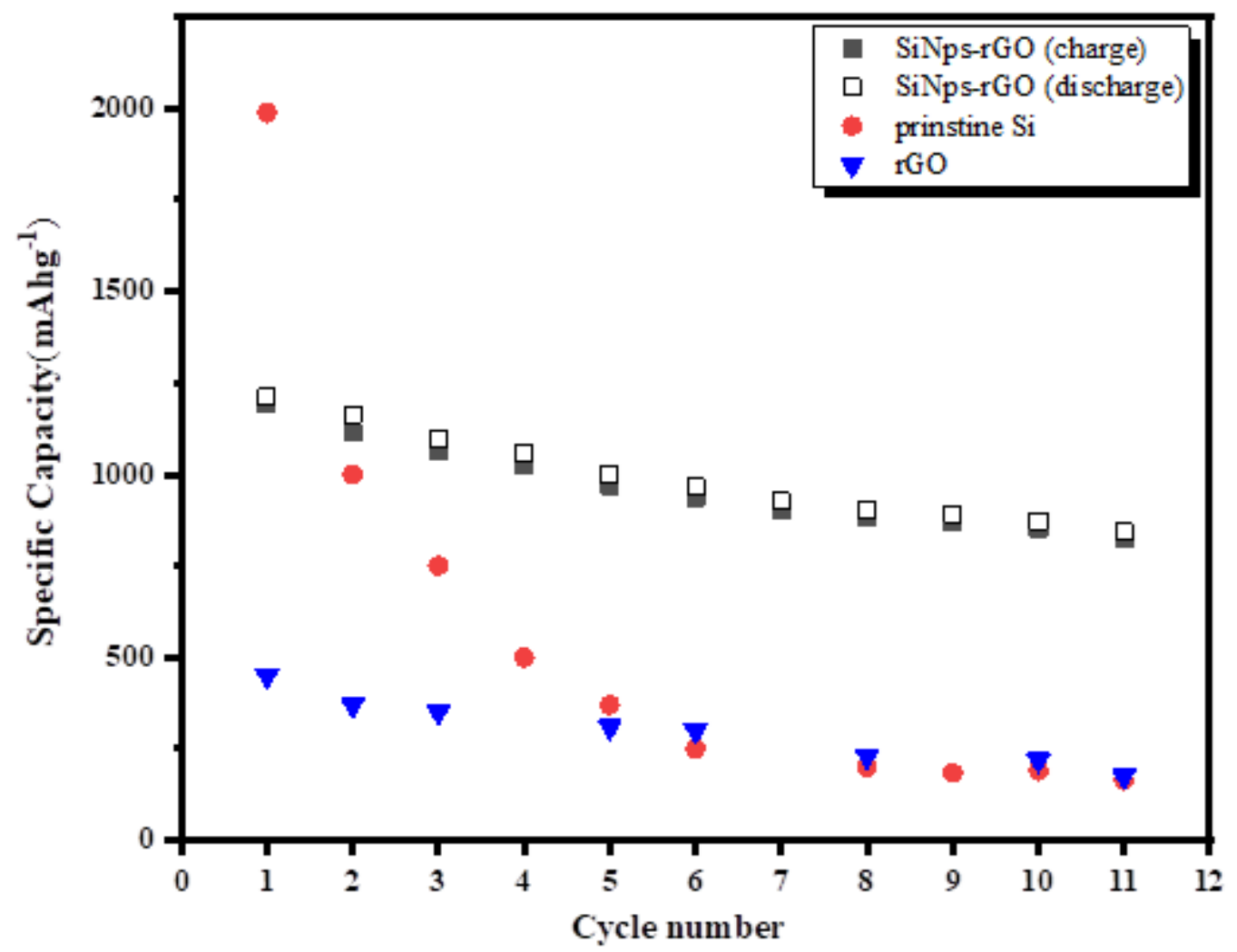

Figure 11

Cycling performance as a function of cycle numbers for the SiNPS-rGO, raw Si, and rGO between 0.001 and $3.0 \mathrm{~V}$ for Synthesis 1. 